\title{
¿Eran de barro nuestros maestros? (Sobre las raíces morales e intelectuales de la oposición política al franquismo)
}

\author{
ANTONIO GARCÍA SANTESMASES \\ UNED, Madrid
}

\begin{abstract}
RESUMEN. Este trabajo versa acerca de los orígenes de la disidencia moral y política en la lucha contra el franquismo. En la reciente obra del profesor Santos Juliá Historias de las dos Españas se ha vuelto a tratar este tema, que afecta a la visión de los historiadores sobre nuestro pasado $\mathrm{y}$ que podríamos formular de la siguiente manera: dada la preeminencia de la cultura falangista y del nacional-catolicismo, ¿cómo llegaron a constituir la oposición al régimen los jóvenes hijos de los vencedores?, ¿lo hicieron por sí mismos?, ¿contaron con el apoyo de intelectuales de la generación anterior?, ¿eran de barro intelectuales como Aranguren y Tierno Galván?
\end{abstract}

Vuelve el debate de los historiadores. Un debate alimentado en sus inicios - por citar una fecha- con la polémica del año 1997 acerca de la enseñanza de la historia; un debate que continuó después con el esfuerzo del gobierno del Partido Popular por construir una nueva interpretación de la España de la Restauración, intento que a su vez se solapaba con el choque entre el nuevo nacionalismo español conservador y el nacionalismo periférico; y que sigue,
ABSTRACT. This task deals with the origins of the moral and political opposition against franquism. In the recient book (Stories of the two Spains) of the teacher Santos Julia, again, it's discussed this subject: «in a country where fascism and national-catholicism had all the power, how did the youngsters fight against franquism?, did they have the support of previous decade intellectuals as Aranguren and Tierno Galván? 
recensiones en muchos medios de comunicación. Todo ello obedece, amén de los méritos indudable del libro, a un contexto del que en seguida hablaremos. El propósito de este trabajo no es realizar una recensión, sino reflexionar sobre uno de los temas, que tanto el autor como los comentaristas, han puesto encima de la mesa: el papel de las grandes figuras intelectuales de la generación de la Guerra Civil en el magisterio de las generaciones posteriores.

\section{La tarea pendiente}

El 25 de julio de 1999 Santos Juliá escribía un artículo en el diario El País, que es hoy interesante recordar, porque viene a resumir la misión que se había encomendado a sí mismo como historiador. Una misión en verdad difícil. La pregunta que el diario lanzaba a dos de sus colaboradores (Fernando Vallespín y Santos Juliá) era la siguiente: « $¿$ Olvidar o asumir nuestro pasado inmediato?», y en su respuesta Santos Juliá, tras recordar la efervescencia de la Edad de Plata de la cultura española y examinar la política de liquidación y exterminio de la Dictadura de Franco, resumía el debate que se produjo dentro del franquismo en los años cincuenta entre los que se denominó «Excluyentes» y «Comprensivos» y señalaba refiriéndose a estos últimos: «En su nuevo caminar, sufrieron una considerable metamorfosis: devinieron liberales y demócratas, a la vez que constituían una respetable obra personal y se erigían en mentores de las nuevas generaciones, las nacidas durante o inmediatamente después de la guerra. Pero excepto uno, Dionisio Ridruejo, ninguno de ellos se enfrentó a cara de perro con su pasado católico fascista: ni ellos, ni sus discípulos que tienen aquello como un extravío en el que no es preciso insistim !

A partir de esta primera consideración Santos Juliá afirmaba: «Quizás no sea preciso insistir: sólo insisten los maleduca- dos. Pero por lo que a esta generación se refiere, no es el caso de insistir, sino de conocer, pues los rastros que dejaron en el pasado han quedado como difuminados en sus memorias y recuerdos complacientes, o han sido calificados por sus discípulos como algo episódico o circunstancial que la transición a la democracia, con su exigencia de amnistía general, obligaba a olvidar. Y seguramente fue necesario olvidar como único medio para superar la escisión de la guerra, pero el olvido no se puede construir sobre el hueco de la memoria, sino sobre la comprensión de lo que fue» ${ }^{2}$.

La conclusión del artículo es todo un programa de actuación: «Conocer para comprender: ésa es la tarea todavía pendiente. Nuestro trabajo no es el de juez sino el de hermeneuta. No se trata de remover lo que sus mismos autores tuvieron, cuando demócratas, como basura, para satisfacer no se sabe qué asuntos pendientes. De lo que se trata es de que una comunidad política de ciudadanos libres no puede constituirse sobre la censura del pasado, sobre obras completas cuidadosamente expurgadas. Esa generación intelectual ha desempeñado un alto magisterio y ha cultivado la búsqueda del supremo valor de la verdad: que la verdad se haga sobre su pasado será el mejor homenaje que pueda realizarse a su memoria» ${ }^{3}$.

\section{El contexto}

Antes de entrar a discutir la tesis más polémica contenida en esta Historias de las dos Españas hay que dar cuenta del éxito editorial del libro; éxito debido, amén de los méritos indudables del mismo, al contexto que estamos viviendo en los últimos años. El 12 de octubre del 2004, el día de la Hispanidad, Olegario González de Cardedal publicaba un artículo titulado «¿Qué España?», donde lanzaba una crítica que parece escrita pensando en Santos Juliá, aunque, en aquel momento no había 
aparecido su obra. Decía el conocido teólogo que los españoles «[...] de tiempo en tiempo deciden abolir la historia, cambiar el presente y comenzar a construir el país como si nada se hubiera hecho hasta entonces [...] se eleva a categoría absoluta un momento de la historia anterior, a partir de él se descartan los demás y con él como modelo se configura una nueva legislación, una cultura y una comprensión de la ciudadanía, convirtiéndola en criterio de dignidad y de exclusión» ${ }^{4}$. ¿Cuál es ese momento de la historia que se pretende rescatar? Para Olegario González de Cardedal está claro: «[...] la glorificación incondicional y repetida día tras día de la segunda república española. Previamente se parte de un presupuesto que nadie se atreve a confesar explícitamente: que la transición constitucional del 78 no fue suficientemente radical, porque se careció del coraje necesario para hacer la revolución imprescindible y sin la cual España no estaría resanada. A partir de ahí se vuelve la mirada a los primeros años treinta, se pone como modelo limpio de toda sospecha a sus hombres e instituciones, dándose por supuesto que todo aquello fracasó por motivos impuros, interesados $\mathrm{y}$ violentos [...] ese modelo de política, de cultura y de sociedad ensoñado e históricamente falso es el que se propone ahora para una España regional, republicana, agnóstica» 5 .

Creo que excepto V. Navarro y algunos más son muy pocos los que apuestan explícitamente por lo que dice $\mathrm{O}$. González de Cardedal, pero por aquello de que es siempre bueno ponerse la venda antes de la herida, se está produciendo una auténtica catarata de obras contra la Segunda República y sus hombres. Estamos es un momento donde los libros de Pío Moa se venden por decenas de miles, y merecen el elogio apasionado de liberales como Pedro Schwartz. Schwartz considera, al igual que González de Cardedal, que la interpretación dominante de la his- toria de España sigue siendo favorable a la Segunda República española y crítica con la monarquía de la Restauración y con la época franquista, por ello no se reprime al elogiar a Pío Moa porque éste: $«[. .$.$] re-$ presenta una interpretación distinta que obedece a una interpretación liberal, trágicamente liberal, de nuestra historia contemporánea. Para Moa la caída de la monarquía de la restauración supuso la derrota del liberalismo, bajo el asalto sin piedad de los nacionalismos periféricos, del obrerismo revolucionario del PSOE y los anarquistas y del anticlericalismo militante de los republicanos. Todos ellos movimientos en los que el individuo queda subsumido en las grandes colectividades tribales y clasistas, que le negaban la libre elección de sus creencias. El fracaso de la república demostró para Moa la ausencia de una alternativa viable al sistema político de la restauración, que al menos había subsistido durante medio siglo y enmarcado un notable progreso económico y social del país. La guerra civil no era inevitable y la declararon las izquierdas y los nacionalistas catalanes al levantarse contra la república burguesa y liberal en la mal llamada revolución de Asturias del 34. Franco, por suerte o por desgracia, dejó una España mucho más avanzada de la que había recibido. La transición tuvo un éxito inesperado y la Constitución del 78 un efecto constructivo, que ha contribuido a hacer de España un país por fin a la altura de los vecinos europeos. El futuro, sin embargo, está cargado de nubarrones por el renacimiento del dogmatismo izquierdista y anticlerical, $y$, sobre todo, por el reverdecer de nacionalismos minoritarios empeñados en la ruptura de pacto constitucional» ${ }^{6}$. Esto lo dice un liberal como Pedro Schwartz a la vez que añade: «mientras [Pío Moa] vende decenas de miles de ejemplares de sus libros, el silencio de los corderos se extiende como una espesa y maligna niebla sobre su obra» $?$. 
No sé si el libro de Santos Juliá o el último premio Anagrama, concedido a Jordi Gracia, llegarán a alcanzar un día en el número de ventas a Pío Moa pero es evidente que una parte de la opinión pública española estaba demandando al menos un contrapunto. Se ha escrito tanto acerca de las bondades de Cánovas; se ha teorizado tanto sobre la homología entre la España de la Restauración y las democracias europeas de la época; se ha anatematizado tan virulentamente a la Segunda República como un experimento totalitario, y se ha cargado toda la responsabilidad de la guerra civil española en los acontecimientos vividos en Asturias y en Barcelona en 1934, que era imprescindible hallar una alternativa a tanto desvarío.

El libro de Santos Juliá lo intenta y es de justicia señalar que - buen conocedor de Azaña - logra restaurar la verdad de los vencidos en la guerra civil, una verdad masacrada por años y años de manipulación, una verdad que hoy vuelve a ser puesta en cuestión.

Ése es su mayor mérito: reconstruir la efervescencia cultural de la llamada «Edad de Plata» y recordar cómo ese mundo plural fue liquidado por los vencedores de la guerra civil.

Santos Juliá tiene una larga obra detrás, obra en la que sobresale, a mi juicio, su estudio sobre Manuel Azaña. Quizás por ello, para el que haya leído sus libros sobre el Frente Popular, sobre la izquierda del PSOE en los años treinta, y conozca su historia de los socialistas en la política española, los primeros capítulos de la obra tendrán menos interés. Y, sin embargo, son lo mejor del libro.

Santos Juliá irrumpe a final de los años setenta con sus libros sobre el Frente Popular, y logra sobresalir, a principio de los noventa, con su biografía de Azaña. A partir de un determinado momento comienza, sin embargo, a centrar su investigación en la pregunta acerca del papel de la memoria en la construcción de la demo- cracia española. Cuatro trabajos ayudan a entender el sentido de esta obra. Nos referimos a su participación como editor de dos publicaciones acerca de la Violencia en la política española y Las víctimas de la represión y de dos artículos acerca de «La memoria en la transición: el esfuerzo por echar al olvido» y « ¿Falange liberal o intelectuales fascistas?» ${ }^{8}$. Es como si el primer Santos Juliá, al escribir en un contexto de hegemonía intelectual del marxismo, se centrara en los avatares de la izquierda socialista de los años treinta y el actual, consciente de la relevancia de los nacionalismos, tratara de responder a la pregunta de si el tradicional interrogante acerca del ser de España se mantiene o ha ido desapareciendo; tratara de saber si la pregunta por la esencia, la identidad, las raíces y el futuro de las naciones se ha trasladado del nacionalismo español a los nacionalismo periféricos ${ }^{9}$.

El libro abarca dos temas. El primero remite a los relatos que se han construido sobre la Historia de España, y el segundo, al papel de los intelectuales en la España contemporánea. Los relatos se remontan a la polémica a lo largo del siglo XIX entre liberales y tradicionalistas, entre progresistas y católicos, entre modernizadores e integristas. Por las páginas de este libro van apareciendo las Cortes de Cádiz, los liberales, los afrancesados, la frustración absolutista, el exilio, las guerras civiles, Balmes, Donoso Cortés, Menéndez Pelayo, el fracaso de la Primera República, la España de la Restauración, la Institución Libre de Enseñanza, la Generación del 98, la Generación del 14 y, dentro de ella, la bifurcación que se va a dar entre las dos grandes figuras de esa generación, entre Ortega y Azaña. Aparece, muy bellamente expuesto, el momento en que irrumpe Ortega con 23 años desafiando a la generación anterior, y la el momento en que todos son conscientes de que la revelación de la República se centra en la figura de Manuel Azaña. 
Todos los que nos sentimos, de una manera $u$ otra, deudores del pensamiento y de la esperanza que supuso Manuel Azaña y la Segunda República española no podemos sino sentirnos reconocidos en estas páginas. Reconocimiento que Santos Juliá ha hecho extensivo a figuras que han preservado el legado republicano, como Juan Marichal o Francisco Ayala.

\section{El capítulo más polémico}

En la recensión a esta obra publicada en el diario El País, recensión que tendré muy en cuenta de cara a la reflexión que quiero desarrollar, José Álvarez Junco ya advertía que el capítulo más polémico era el último, al narrar el papel de los intelectuales más significativos durante los años cuarenta. A fin de cuentas, decía, fueron nuestros maestros. Retengamos la frase exacta de Álvarez Junco: «Tras estas páginas magistrales vienen las más polémicas: el capítulo sobre los falangistas "liberales", tema que ya ha hecho correr bastante tinta en el pasado. Fueron nuestros maestros y es natural que susciten pasiones» ${ }^{10}$. El mismo Álvarez Junco, a la muerte de Luis Díez del Corral, había escrito: «Díez del Corral perteneció a la generación y al grupo de amigos de Maravall, Aranguren, Laín o Ridruejo. Difícilmente sabremos estar a su altura» 11.

La tesis de Santos Juliá en esta obra la resume muy bien Álvarez Junco: «A partir de una documentación de primera mano, Santos Juliá aborda de manera compleja, desprovisto de intención tanto inquisitorial como exculpatoria, el miserable ambiente cultural de los años cuarenta y la actuación de quienes se mostraron menos intolerantes hacia los vencidos», y se pregunta: «¿Cómo pudo surgir la oposición al franquismo, de qué fuentes intelectuales bebió? Frente a cualquier continuidad con la tradición liberal o con los republicanos del exilio, Santos Juliá, en unas páginas apasionantes que tienen mucho de auto- biográfico, lo relaciona con el propio falangismo y catolicismo del interior, con las exigencias de autenticidad de unos jóvenes que se tomaron en serio el único mensaje político existente. Había sido tan grande la apuesta, tanta la justicia social e integración nacional prometidas, que fue inevitable que los más honestos descubrieran y denunciaran el fracaso del régimen» 12 .

El libro termina con la aparición de la Generación del 56 y con el influjo que va a tener en los años sesenta, llegando incluso a referirse en algunos momentos a acontecimientos de los años setenta. Es aquí, como vamos a tratar de demostrar, donde se encuentra el mayor desacierto de la obra, porque, al tratar de extender a los años sesenta y setenta la vivencia de 1956 , se corre el peligro de equiparar momentos muy diferentes y de equiparar también personalidades muy distintas. No creo que tuvieran la misma influencia en las generaciones antifranquistas de los años sesenta y setenta Laín Entralgo, Tovar, Aranguren o Tierno Galván. Si nos atenemos a la definición de intelectual que da Santos Juliá: el que tiene algo que decir a través de los medios de comunicación, Tierno conservó un gran protagonismo político hasta su muerte y Aranguren participó muy activamente en los medios de comunicación desde los inicios de la transición, singularmente en el diario El País. No fue el caso de Tovar ni de Laín. Ridruejo fallece antes de morir Franco ${ }^{13}$

Dice Álvarez Junco que Santos Juliá no tiene una intención exculpatoria ni inquisitorial a la hora de valorar lo que fue la actuación de los falangistas «liberales» en los primeros años del franquismo. Exculpatoria claramente no la tiene, porque el autor se había propuesto como tarea contribuir a constituir una comunidad de ciudadanos capaces de mirar al pasado. Santos Juliá considera que se ha tejido una leyenda en torno a este grupo generacional 
pretendiendo que siempre fueron liberales. Nada más lejos de la realidad - afirma contundentemente-, fueron falangistas que, en aquel contexto de la guerra civil, trataron de romper radicalmente con la España liberal y con la España republicana y construir una nueva España a partir de la depuración de todo vestigio de liberalismo. Es una leyenda posterior, edificada por la benevolencia con su pasado y con la inhibición de sus discípulos, la que pretende que ya entonces eran liberales, tolerantes. y comprensivos. Santos Juliá piensa que la evolución posterior de estos falangistas hacia el liberalismo, y la conversión al marxismo de algunos jóvenes falangistas, ha provocado que parezca que en España nadie fue fascista en los primeros años del régimen ${ }^{14}$.

Santos Juliá va dibujando la estrategia del grupo de Escorial en el choque que tiene con los tradicionalistas de Acción Española. Tras la unificación política del 37 la batalla la pierden los falangistas con la caída de Serrano Suñer en 1942, pero tampoco la ganan los tradicionalistas, que son sustituidos por los católicos. La hora de los católicos llega con la derrota de Alemania e Italia tras la Segunda Guerra Mundial. El Vaticano es el gran embajador ante Estados Unidos y ambos serán decisivos para la legitimación del régimen en la hora de la guerra fría.

El grupo falangista, que había quedado derrotado tras la caída de Serrano Suñer, vuelve a tener una oportunidad en 1951 cuando Joaquín Ruiz Jiménez (un católico) es nombrado ministro de Educación y recurre a algunos de estos prohombres falangistas como Laín y Tovar para hacerse cargo de los rectorados de las universidades de Madrid y de Salamanca. De nuevo aquí, el esfuerzo de estos falangistas de incorporar parte del legado de las generaciones anteriores a la guerra civil choca con la posición excluyente de los tradicionalistas. Tras la caída del ministerio de Ruiz Jiménez, Tovar y Laín se retiran al trabajo científico y no vuelven a tener protagonismo político.

Con el final de aquel experimento se produce la irrupción de una nueva generación que se encuentra alejada de toda la retórica de las dos Españas, y de todas las peleas dentro del régimen. Unos evolucionarán hacia el marxismo y otros mantendrán su catolicismo pero dándole un signo completamente distinto. En las páginas de este último capítulo, en esas páginas que según Álvarez Junco tienen mucho de autobiográfico, Santos Juliá se pregunta cómo es posible que sólo en diez años se pasara de aquella situación de los años cincuenta, en que todos eran católicos, a un nuevo mundo donde en 1966 Semprún podía hablar de la aparición de una nueva generación marxista en España. Aquellos jóvenes rompieron con la generación anterior, con el régimen y sus querellas, y descubrieron que lo tenían que hacer todo por sí mismos, descubrieron que los maestros eran de barro ${ }^{15}$.

Al situar estas páginas, como teñidas por la autobiografía, es cuando uno queda más desconcertado. Es posible que la vivencia de Santos Juliá haya estado fundada en un trabajo «de base» de católicos y comunistas, de cristianos y marxistas, y es posible que para esa tarea la perspectiva de los falangistas de los años cuarenta quedara muy atrás. Desde luego muchos de ellos habían evolucionado hacia un liberalismo muy alejado de esa síntesis entre cristianismo y marxismo que demandaban las nuevas generaciones, y estaban refugiados en su tarea académica.

Sería interesante saber cómo se produjo la evolución de jóvenes falangistas como Carlos París, Manuel Sacristán o Miguel Sánchez Mazas hasta pasar a la oposición antifranquista. Cuando escribo estas líneas se anuncia una biografía de Juan Ramón Capella sobre Manuel Sacristán que puede aclarar muchas cosas en este sentido. Por lo demás es evidente que alguno de ellos, como Sacristán, sería re- 
conocido como maestro por toda una generación de pensadores marxistas (Juan Ramón Capella, Francisco Fernández Buey, Toni Domenèch, Víctor Ríos, Rafael Grasa) ${ }^{16}$.

Es evidente que Santos Juliá no tuvo ninguna relación directa de discipulado con los maestros de la generación anterior al modo como sí la tuvo Elorza con Maravall, Álvarez Junco con Díez del Corral, Sotelo con Dionisio Ridruejo y Pedro Laín, Elías Díaz con Joaquín Ruiz Jiménez y Enrique Tierno Galván, o Javier Muguerza y X. Rubert de Ventos con José Luis Aranguren. Todos ellos han escrito sobre sus maestros. Santos Juliá les reprocha no haber sido capaces de enjuiciar críticamente el pasado de sus mentores. Quizás prefiere por ello obviar todos estos nombres y centrarse en aquellos que tuvieron que empezar a construir su propio pensamiento, sin contar con ningún tipo de apoyo.

Al optar por esta estrategia interpretativa, al negar la continuidad con aquellos intelectuales, se corre el peligro de malinterpretar lo que realmente ocurrió. S. Juliá se centra en la evolución del mundo católico a lo largo de estos años. Un mundo que con el tiempo llegará a producir declaraciones colectivas como la formulada por la Asamblea conjunta de obispos y sacerdotes en 1971 o el primer manifiesto de Cristianos por el Socialismo en 1972. Al adentrarse por esos caminos es inevitable preguntar: ¿es posible entender la evolución de ese mundo sin tener en cuenta el magisterio de Aranguren?

El problema es que para hacer veraz la tesis de la ausencia de maestros no se mencionan obras esenciales en el pensamiento español de los años sesenta, en lo que E. Díaz ha llamado la «reconstrucción de la razón». En ningún momento se habla de libros como Ética y política, La crisis del catolicismo y El marxismo como moral, de J. L. Aranguren ${ }^{17}$. Por no hablar que ni siquiera se menciona que Arangu- ren, Tierno Galván y García Calvo fueron expulsados de sus cátedras en el año 1965. De Tierno tampoco se menciona ni Humanismo y sociedad, Razón mecánica y razón dialéctica ni Qué es ser agnóstico ${ }^{18}$.

Evidentemente, el autor no tiene por qué mencionar todas las obras, pero me parece que es muy difícil entender la reconstrucción del pensamiento español sin tener en cuenta a Aranguren y Tierno. Tierno no aparece y Aranguren es sometido a un extraño juicio donde continuamente se le acusa de borrar las huellas de su pasado, de releer a la luz de lo que llegó a ser después sus experiencias anteriores, de hurtar el cuerpo y no querer asumir su historia ${ }^{19}$.

Nos puede parecer que sigue siendo un misterio la actuación de Aranguren durante la guerra civil. Nos puede parecer extraño que en aquel momento, de extrema polarización, un hombre que llegaría a tener un protagonismo público tan acentuado décadas después se centrara en la espiritualidad y en la mística. Sin embargo, hay un punto que no debemos olvidar. A diferencia de Ridruejo, de Tovar, de Laín o de Torrente, Aranguren empieza mucho más tarde su andadura pública y por eso mismo, como vio muy acertadamente Ignacio Sotelo ${ }^{20}$, de alguna manera llega nuevo a 1955, llega como un escritor católico, preocupado por el debate con el existencialismo, sobre la relación entre Ortega y el cristianismo, y se encuentra, como él mismo ha dicho, con unos jóvenes estudiantes que le piden que les hable del marxismo, de la teoría crítica de la sociedad, de la filosofía analítica, de la crítica literaria, de algo muy alejado a los intereses de su generación. Esa capacidad para poder sentirse interpelado por los jóvenes estudiantes es la que le va hacer sentirse reconocido como «maestro» por discípulos como Ignacio Sotelo, Luis Gómez Llorente, Javier Muguerza, Luis García San Miguel, Víctor Pérez Díaz, Xavier Rubert de Ventos, Jesús Aguirre, 
Elías Díaz. Son demasiados nombres relevantes para afirmar que todos los maestros eran de barro ${ }^{21}$.

La misma situación encontramos en Tierno. Pensar que nombres como Fernando Morán, Raúl Morodo, Pedro de Vega, Elías Díaz, son explicables sin tener en cuenta el magisterio de Tierno es insostenible ${ }^{22}$.

Se podría decir que todo esto ocurre en el mundo académico, pero es que justamente el mundo universitario, con los sectores cristianos y el nuevo movimiento obrero, son los que se movilizan contra el régimen de Franco.

Creo que esta tesis de la obra de Santos Juliá puede provocar grandes equívocos en algunos lectores, que pueden llegar a la conclusión de que todos eran franquistas hasta un determinado momento, y los que dejaron de serlo no influyeron en el mundo posterior. El franquismo de los miembros de Escorial es innegable, pero, no se puede dar el mismo protagonismo a los miembros del servicio de propaganda en Burgos que a una persona que estaba recluida en su vida privada, porque pensaba que nunca tendría un protagonismo público o a un vencido de la guerra civil que tiene que simular para poder subsistir.

\section{IV. ¿Desaparecen los grandes relatos?}

Me parece que esta carencia de la obra de Santos Juliá responde a una tesis que está en la obra y con la que ésta concluye. La obra trata de estudiar la evolución de los intelectuales en la España contemporánea y de descifrar los relatos que se han ido dando sobre esta historia. Todo el esfuerzo del autor se centra en elogiar a la Generación del 56 por ser capaz de superar el lenguaje de la guerra civil, y por trascender la concepción de la política como una actividad dicotómica donde sólo cabe vencer o morir, triunfar o perecer. La superación de la guerra civil en un nuevo lenguaje, en un lenguaje que utilizan a la par los hijos de los vencedores y de los vencidos, está detrás de la apuesta por la reconciliación. A partir de ahora ya no habrá grandes relatos sobre España, se abominará de la guerra civil como de una guerra fratricida y sólo se utilizará el lenguaje de la democracia.

La sorpresa se acrecienta por ello al final. Al redescubrir el lenguaje de la democracia y la conexión de España con Europa la Generación del 56 selló una aportación innovadora en la vida española. Es justo reconocer el papel de personas, hoy desconocidas para muchos, que hicieron una gran contribución a la lucha por la democracia. Pienso por ejemplo en Miguel Sánchez Mazas. La sorpresa viene porque tanto Aranguren como Tierno escribieron páginas muy profundas acerca del paso de la época de las grandes ideologías a la era de la tecnocracia y la despolitización.

Ambos, desde perspectivas distintas (cristiana heterodoxa en el caso de Aranguren y socialista marxista en el de Tierno), veían como una rémora del pasado toda aquella mística de la guerra civil, pero observaban el peligro de la tecnocracia del «Estado de Obras» (que también defendía «un crepúsculo de las ideologías"), y analizaron los efectos de la desideologización de todo Occidente en lo que denominaron «materialismo consumista» $\mathrm{y}$ «humanidad reducida». Frente a ellos proponían «la democracia como moral» y «la revolución cultural». En aquel mundo de esperanza de los años sesenta, en aquel mundo donde florecieron las mejores utopías, supieron conectar con los nuevos movimientos cristianos y con el socialismo mediterráneo. Quizás hoy no quede mucho de aquel mundo de los años sesenta, pero gracias a esa apuesta pudieron conectar a partir de 1968 con nuestra generación. No fueron nuestros maestros directos, dado que estaban expulsados de la universidad, pero su figura adquirió para todos nosotros una dimensión esencial como referentes del antifranquismo. 
Álvarez Junco en el comentario de esta obra, y lo utilizo profusamente porque es de una gran ayuda para discutir la tesis de Santos Juliá, afirma: «En su conjunto, el libro me parece la mejor síntesis de la historia intelectual española de los dos últimos siglos [...] Un libro indispensable, en suma, para el que quiera entender cómo hemos llegado a ser lo que somos, o pensar políticamente lo que pensamos. Lo que somos y pensamos, o lo que hemos sido y pensado los que ya no podemos presumir de jóvenes. Porque éste no es un libro de actualidad, sino un libro de historia. Afortunadamente salvo en ambientes nacionalistas periféricos, pocas de estas grandes disquisiciones sobre la patria esencial siguen candentes. Vivimos sanos tiempos de pensamiento débil, de fragmentación, de mirada distanciada y burlona hacia la epopeya nacional. Este Rip sobre el "gran relato" nacional es, quizá, nuestro gran relato, la seña de identidad generacional de quienes surgimos a la vida política e intelectual en el último franquismo» ${ }^{23}$.

Meditando sobre el sentido de estas palabras se puede evaluar mejor las luces y las sombras de la tesis que contiene esta obra y juzgar en qué medida Santos Juliá ha cumplido con la tarea que se había asignado a sí mismo y de la que hablábamos al principio. Álvarez Junco habla del interés de este libro para llegar a entender cómo hemos llegado a ser lo que somos y a pensar lo que pensamos. El problema es que identifica este ser y este pensar con un pensamiento débil, alejado de los grandes relatos.

No puedo sino discrepar. Lo que hoy estamos viviendo es algo bien distinto. No sólo asistimos a un reverdecer de la preocupación por la identidad nacional por parte de los nacionalismos periféricos, sino a la asunción conservadora de una interpretación de la historia de España (lo veíamos en los textos de Schwartz y de González de Cardedal), que, a modo de un nuevo gran relato, pretende continuar la historia de España, como Cánovas hizo en su día. La Restauración es el paradigma y la República el extravío. Esa vuelta a una lectura de la historia de España «sin complejos» va unida a una crítica a la izquierda como depositaria de una ideología totalitaria causante de la guerra civil. Frente a este desvarío es importante la reivindicación de la memoria republicana. Santos Juliá lo hace en su libro y es lo mejor de la obra.

Pero la pregunta es: ¿esa apuesta por la racionalidad liberal, laica, secular se identifica con la fragmentación, la posmodernidad y el pensamiento débil? Creo que no. Aquí es donde está el problema. ¿No es esa asunción acrítica de la democracia realmente existente la que no le permite captar todas las potencialidades del cristianismo de resistencia y del socialismo utópico de finales de los sesenta? Ésas fueron las apuestas con las que Aranguren y Tierno supieron conectar con la juventud del 68. Gracias a esas apuestas fueron leídos, comentados y seguidos en aquellos años y lo serían hasta su muerte. Ambas apuestas estaban muy alejadas del pensamiento débil, de la fragmentación y de la posmodernidad, y estaban cerca de la voluntad de resistencia, de la modernidad reflexiva y de la totalización crítica. Son su mejor legado y, sin embargo, no aparecen en este libro. Algo muy importante falla cuando esta perspectiva ético-utópica de los grandes maestros de los años sesenta y setenta ni siquiera es mencionada ${ }^{24}$. 
1 S. Juliá, «Restos del pasado», El País, 25 de julio de 1999. S. Juliá ha desarrollado esta tarea en su libro Historias de las dos Españas, Madrid, Taurus, 2004

2 S. Juliá, «Restos del pasado», El País, 25 de julio de 1999.

3 S. Juliá, «Restos del pasado», El País, 25 de julio de 1999.

4 O. González de Cardedal, «Qué España», El País, 12 de octubre de 2004.

5 O. González de Cardedal, "Qué España», El País, 12 de octubre de 2004

6 P. Schwartz, «Pío Moa y los nacionalismos», La Vanguardia, 29 de diciembre de 2004

7 P. Schwartz, «Pío Moa y los nacionalismos», La Vanguardia, 29 de diciembre de 2004

8 S. Juliá (ed.), Violencia política en la España del siglo XX, Madrid, Taurus, 2000; Victimas de la guerra civil, Madrid, Temas de Hoy, 1999. Igualmente los trabajos «iFalange liberal o intelectuales fascistas?», Claves de la Razón Práctica, núm. 121, y «Echar al olvido. Memoria y amnistía en la transición», Claves de la Razón Práctica, núm. 129.

9 S. Juliá, «Las naciones frente al Estado», El País, 5 de enero de 2003.

10 J. Álvarez Junco, «El camino hacia una estrella», El País, 20 de noviembre de 2004.

"I. Álvarez Junco, «Prestancia», El País, 14 de abril de 1998. Es interesante el artículo porque refleja toda una autocrítica a aquel mundo lleno de pasión del último franquísmo, donde, a juicio de Álvarez Junco, los estudiantes comprometidos no eran capaces de aceptar la excelencia que habitaba a su alrededor: «me impresiona, una vez más, nuestra ceguera, la de la juventud antifranquista, obsesionada por las urgencias de la lucha inmediata e incapacitada para apreciar cualidades y valores que - en cantidades poco abundantes, sin duda - existían a nuestro alrededor. Estos valores que hoy desaparecen con Díez del Corral son los del intelectual que es a la vez de excelente calidad y gran señor, que sabe leer, escribir, pensar y hacer pensar a otros, sin contorsiones, sin alterar la voz, sin imponer su autoridad, sin dar espectáculo ni escándalo. Con calma y elegancia, lo que le gustaba era profundizar en los grandes problemas, no dejarse urgir por las presiones cercanas. Nunca le intereso el cotilleo de la oposición al régimen, ni el último manifiesto o reunión clandestina $[\ldots] \gg$.

$12 \mathrm{~J}$. Álvarez Junco, «El camino hacia una estrella», El País, 20 de noviembre de 2004.

${ }^{13}$ Dada la definición de intelectual de Santos Juliá como el hombre que interpreta la realidad, que juega con los significados simbólicos, que interviene activamente en la vida pública, haciendo oír su voz en cada coyuntura, en la medida en que todo intelectual es mediático (Historias de las dos Españas, p. 13), no cabe duda que de todos los miembros de su generación es Aranguren el que juega ese papel de una manera más clara durante la España de la transición, a través del periódico que va a ser el buque insignia de la misma, es decir, a través de las tribunas que va publicando en el diario El País. Próximamente aparecerá un volumen donde se recogen las intervenciones más importantes de Aranguren durante los años 19821996: José L. Aranguren, La izquierda, el poder y otros ensayos, ed. de Antonio García-Santesmases, Madrid, Trotta, 2005.

${ }^{14}$ S. Juliá, Historias de las dos Españas, p. 453 : «tan fuerte fue esa recusación de su propio pasado que dífícilmente se encuentra algún marxista español procedente de Falange que reconozca abiertamente su primera militancia fascista y ofrezca una interpretación plausible de su itinerario político: sencilla mente nunca lo fueron $o$, si lo fueron, fue por despiste. Y como algo similar ocurrió con los fascistas que devinieron liberales, dentro de poco resultará que en España, en los primeros veinte años del Régimen, no hubo verdaderos falangistas, que todo el mundo estuvo en aquellas organizaciones camuflando otra realidad; que eran, en el fondo, liberales o marxistas».

${ }^{15} \mathrm{~S}$. Juliá, Historias de las dos Españas, como escribirá Juan Benet recordando este momento: por más que se empeñen a pasarlas al mármol, «las grandes figuras de nuestra juventud eran todas de barro", p. 432 .

16 Para conocer la evolución del pensamiento de Manuel Sacristán es imprescindible el núm. 30-31 de la revista Mientras Tanto, Barcelona, 1986. Igualmente el volumen Acerca de Manuel Sacristán, de Salvador López Arnal, Barcelona, Ediciones Destino, 1996.

${ }^{17}$ La crisis del catolicismo, de J. L. Aranguren, está recogido en el vol. 1 de sus obras completas en Editorial Trotta, Ética y política y El marxismo como moral en el vol. 3. Es importante tener en cuenta las fechas: La crisis del catolicismo es de 1969, El marxismo como moral de 1968, Ética y política de 1963

18 E. Tierno Galván, Humanismo y sociedad, incluido dentro del volumen Sobre la novela picares ca y otros ensayos, Madrid, Tecnos, 1974, y Razón mecánica y Razón dialéctica, también en Madrid, Tecnos, 1969, al igual que Qué es ser agnóstico. Madrid, 1975. Es interesante de Tierno igualmente: Sobre la evolución de mi pensamiento intelectual, de 1973 , incluido en el volumen Sobre la novela picaresca y otros ensayos.

19 Historias de las dos Españas, pp. 432-433. especialmente en el siguiente párrafo al hablar de la polémica con González de Cardedal acerca de las 
conversaciones católicas de Gredos. Cardedal le reprocha a Aranguren haber malinterpetado aquellas conversaciones, ya que «releyó su historia anterior la luz de su posterior actitud», y añade Santos Juliá «ejercicio en el que llegó a ser verdadero maestro».

${ }^{20}$ Para conocer la evolución de Aranguren es esencial todo el núm. 15 de la revista Isegoría. Santos Juliá no hace mención de ninguno de los artículos que aparecen en el mismo. El trabajo de Ignacio Sotelo «Aranguren y el papel del intelectual» me parece especialmente penetrante para captar la diferencia entre Atanguren y otros miembros de su generación: «Sólo teniendo en cuenta lo que me gustaría llamar su larga etapa silenciosa cabe entender, una vez que toma conciencia de la misión del intelectual, los escritos y la actualización de la pública. Lo que entonces llamó la atención -y sigue llamándola treinta y tantos años más tarde - es la libertad con que salta a plazuela pública, para utilizar la expresión de Ortega sin el menor temor, sin la menor mala conciencia. Aranguren entra en la vida española en los años cincuenta con la que me atrevería a llamar una ingenuidad casi virginal, que se revelaría tan oportuna como fructífera. Perteneciendo al bando de los vencedores, por origen social y sobre todo por su condición de católico, no había intervenido en nada ni escrito nad que desde la derecha o desde la izquierda se le pudiera reprochar. Aranguren, en su generación y dentro de su grupo social, es de los pocos hombres públicos que no han tenido que "descargar su conciencia" en uno u otro sentido, al haber permanecido callado durante los años trágicos de la vida española» (p. 210).

21 Es el mismo Aranguren el que da cuenta de esta relạción especial con sus «discípulos» en Memorias y esperanzas españolas, p. 210 , de la edición de las Obras Completas, t. VI, Madrid, Trotta, 1996. El libro es de 1969.

22 El núm. 71-72 de la revista Sistema está dedicado a la memoria de Enrique Tierno Galván, «El hom bre, el intelectual, el político», con colaboraciones de R. Morodo, E. Díaz, M. Medina, F. Bobillo, S. Giner, J. Muguerza, V. Girbau, L. García San Miguel, F. Bustelo. Se puede consultar el libro de J. Novella Sobre el pensamiento ilustrado de Enrique Tierno Galván, Madrid, CEC, 2001, y la obra de Fernando Morán Una luz al fondo del túnel, Madrid, Alianza Editorial, 1999

${ }^{23}$ J. Álvarez Junco, «El camino hacia una estrella», El País, 20 de noviembre de 2004

${ }^{24} \mathrm{E}$. Díaz ha estudiado magistralmente esta dimensión ético-utópica en el pensamiento de Aranguren en su trabajo «La democracia como moral», en el núm. 15 (dedicado a Aranguren) de la revista Isegoria, y del pensamiento de Tierno en «Tierno Galván: entre el fraccionamiento y la totalidad», en el núm. 71-72 de la revista Sistema (dedicado a Tierno). 